NASA/TM-2002-211592

\title{
Turbulence Measurements of Separate Flow Nozzles With Mixing Enhancement Features
}

James Bridges and Mark P. Wernet

Glenn Research Center, Cleveland, Ohio 
Since its founding, NASA has been dedicated to the advancement of aeronautics and space science. The NASA Scientific and Technical Information (STI) Program Office plays a key part in helping NASA maintain this important role.

The NASA STI Program Office is operated by Langley Research Center, the Lead Center for NASA's scientific and technical information. The NASA STI Program Office provides access to the NASA STI Database, the largest collection of aeronautical and space science STI in the world. The Program Office is also NASA's institutional mechanism for disseminating the results of its research and development activities. These results are published by NASA in the NASA STI Report Series, which includes the following report types:

- $\quad$ TECHNICAL PUBLICATION. Reports of completed research or a major significant phase of research that present the results of NASA programs and include extensive data or theoretical analysis. Includes compilations of significant scientific and technical data and information deemed to be of continuing reference value. NASA's counterpart of peerreviewed formal professional papers but has less stringent limitations on manuscript length and extent of graphic presentations.

- TECHNICAL MEMORANDUM. Scientific and technical findings that are preliminary or of specialized interest, e.g., quick release reports, working papers, and bibliographies that contain minimal annotation. Does not contain extensive analysis.

- CONTRACTOR REPORT. Scientific and technical findings by NASA-sponsored contractors and grantees.
- CONFERENCE PUBLICATION. Collected papers from scientific and technical conferences, symposia, seminars, or other meetings sponsored or cosponsored by NASA.

- SPECIAL PUBLICATION. Scientific, technical, or historical information from NASA programs, projects, and missions, often concerned with subjects having substantial public interest.

- TECHNICAL TRANSLATION. Englishlanguage translations of foreign scientific and technical material pertinent to NASA's mission.

Specialized services that complement the STI Program Office's diverse offerings include creating custom thesauri, building customized data bases, organizing and publishing research results ... even providing videos.

For more information about the NASA STI Program Office, see the following:

- Access the NASA STI Program Home Page at http://www.sti.nasa.gov

- E-mail your question via the Internet to help@sti.nasa.gov

- Fax your question to the NASA Access Help Desk at 301-621-0134

- Telephone the NASA Access Help Desk at 301-621-0390

- Write to:

NASA Access Help Desk

NASA Center for AeroSpace Information 7121 Standard Drive

Hanover, MD 21076 
NASA/TM-2002-211592

AIAA-2002-2484

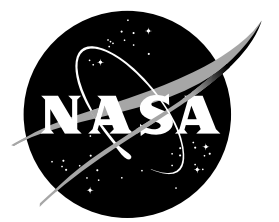

\section{Turbulence Measurements of Separate Flow Nozzles With Mixing Enhancement Features}

James Bridges and Mark P. Wernet

Glenn Research Center, Cleveland, Ohio

Prepared for the

Eighth Aeroacoustics Conference

cosponsored by the American Institute of Aeronautics and Astronautics

and the Confederation of European Aerospace Societies

Breckenridge, Colorado, June 17-19, 2002

National Aeronautics and

Space Administration

Glenn Research Center 


\section{Acknowledgments}

This work was supported by NASA Supersonic Propulsion Base Research program under Mary Jo Long-Davis. The authors thank Dr. Abbas Khavaran for his consultation on the turbulence modeling and aeroacoustic theory.

This report is a preprint of a paper intended for presentation at a conference. Because of changes that may be made before formal publication, this preprint is made available with the understanding that it will not be cited or reproduced without the permission of the author.

Trade names or manufacturers' names are used in this report for identification only. This usage does not constitute an official endorsement, either expressed or implied, by the National Aeronautics and Space Administration.

Available from

NASA Center for Aerospace Information 7121 Standard Drive

Hanover, MD 21076
National Technical Information Service 5285 Port Royal Road Springfield, VA 22100 


\title{
Turbulence Measurements of Separate Flow Nozzles with Mixing Enhancement Features
}

\author{
James Bridges* and Mark P. Wernet* \\ National Aeronautics and Space Administration \\ Glenn Research Center \\ Cleveland, Ohio 44135
}

\begin{abstract}
Comparison of turbulence data taken in three separate flow nozzles, two with mixing enhancement features on their core nozzle, shows how the mixing enhancement features modify turbulence to reduce jet noise. The three nozzles measured were the baseline axisymmetric nozzle $3 \mathrm{BB}$, the alternating chevron nozzle, $3 \mathrm{~A}_{12} \mathrm{~B}$, with 6 -fold symmetry, and the flipper tab nozzle $3 \mathrm{~T}_{24} \mathrm{~B}$ also with 6-fold symmetry. The data presented show the differences in turbulence characteristics produced by the geometric differences in the nozzles, with emphasis on those characteristics of interest in jet noise. Among the significant findings: the enhanced mixing devices reduce turbulence in the jet mixing region while increasing it in the fan/core shear layer, the ratios of turbulence components are significantly altered by the mixing devices, and the integral lengthscales do not conform to any turbulence model yet proposed. These findings should provide guidance for modeling the statistical properties of turbulence to improve jet noise prediction.
\end{abstract}

\section{$\underline{\text { Introduction }}$}

In 1997, as a part of NASA's Advanced Subsonic Technology Program, a series of separate flow nozzle concepts were tested. Concepts based upon the paradigm of noise reduction through mixing enhancement were submitted by General Electric Aircraft Company, Pratt \&Whitney, and Rolls Royce Corporation. Several of these nozzle concepts provided significant noise benefits with negligible thrust penalty. During the 1997 Separate Flow Nozzle Test (SFNT), many measurements were made on the jet flows: far-field acoustics, total and static pressure and total temperature surveys of the plume, infrared imagery of the plume, acoustic source distribution estimation by phased arrays, and Schlieren images ${ }^{1}$. These combined to describe the mean flow field and acoustic fields for the jet flows, leading to some understanding of how changes in the flow field caused beneficial changes in the acoustic sources.

As successful as the 1997 SFNT was, one key class of information was not acquired: turbulence statistics are the main information that aeroacoustic theory requires to relate flow to sound. Specifically, leading theories require two-point space-time correlations of the velocity field as input to predict acoustic output of the jet flow. A second series of tests were performed in 2000 using the SFNT test hardware, the test being called SFNT2K. The datasets for the separate flow nozzle tests now have turbulence measurements, including two-point space correlations, for the three most important nozzle configurations.

\section{Facilities and Instrumentation}

The AST Separate Flow Nozzle Tests were conducted at the AeroAcoustic Propulsion Laboratory (AAPL) at NASA Glenn Research Center in Cleveland, Ohio. The

*AIAA Senior Member. exhaust nozzle models were mounted on a hydrogenfired jet engine exhaust simulator rig inside a freejet, providing a scaled model of engine nozzles at appropriate hot flow conditions in simulated flight.

The Aeroacoustic Propulsion Laboratory (AAPL) at NASA Glenn Research Center is a 65ft radius, anechoic, geodesic dome. Within the acoustically lined confines of the dome is the Nozzle Acoustic Test Rig (NATR), a free-jet, forward-flight-simulation test rig. The NATR extends from an annular air ejector system to a plenum and bellmouth contracting down to the final duct having an exit inner diameter of 53 inches and a nozzle centerline 10 feet above the concrete floor. This arrangement provides a free-jet Mach number up to 0.3 at $300 \mathrm{lbm} / \mathrm{s}$ with the freestream turbulence of less than 1 percent ${ }^{2}$.

Test nozzle models are installed on the aft end of the hydrogen-fired jet exit rig (JER) that is located at the exit of the NATR duct. The core stream of the rig was used to provide the hot core flow, while the fan flow came from a secondary strut into a dual flow 'pod' fastened just aft of the combustor. For the PIV measurements, a choke plate replaced the reticulated foam metal to keep seed from clogging and destroying the foam metal.

Mass flow was measured using a choked-flow venturi located in the 4" supply lines downstream of the fan/core flow split, in the long horizontal pipe runs alongside NATR. Two total pressure and two total temperature rakes (with five elements each) were installed at the charging station of the fan and of the core ducts of the dual flow pod. The fan rakes are installed at circumferential angle positions of $0^{\circ}, 90^{\circ}, 180^{\circ}$, and $270^{\circ}$, while core nozzle rakes are located at circumferential angles of $60^{\circ}, 150^{\circ}, 240^{\circ}$, and $330^{\circ}$.

In these tests, the core and bypass streams were seeded with aluminum oxide $\left(\mathrm{Al}_{2} \mathrm{O}_{3}\right)$ powder using two identical, specially built, fluidized bed seeders. The alumina powder had a specific gravity of 3.96; the 
particle size distribution had a mean of $0.7 \mu \mathrm{m}$ and a standard deviation of $0.2 \mu \mathrm{m}$. The seeders provided roughly 0.5 liters/hour of dry seed particles each, seeding the flow at a rate of $\sim 10$ particles $/ \mathrm{mm}^{3}$. Given the light sheet thickness of $0.2 \mathrm{~mm}$, this produces on the order of 10 particles in a $2 \mathrm{~mm}$ by $2 \mathrm{~mm}$ interrogation region. The ambient flow was seeded by a commercial fogger, Vicount 5000, manufactured by Corona Technologies, Inc. This fogger produced droplets in the $0.2-$ 0.3 micron diameter range at a rate of 5 liters/hour of fluid.

The PIV system was a two-camera system configured to yield two image fields, one above another with a slight overlap. The two $1 \mathrm{~K} \times 1 \mathrm{~K}$ pixel Kodak ES 10 cameras equipped with f/5.6, $85 \mathrm{~mm}$ Nikkor lenses and $8 \mathrm{~mm}$ extension rings were mounted one atop the other 52 inches $(1.32 \mathrm{~m})$ away from the light sheet. The two cameras were positioned to overlap their fields of view by 0.5 inches, yielding a composite field of view 10.5 inches high by 5 inches wide $(0.267 \mathrm{~m} \times 0.127 \mathrm{~m})$. A dual head Nd:YAG laser operating at $532 \mathrm{~nm}$ was used to generate a $400 \mathrm{~mJ} /$ pulse light sheet. The laser, cameras, and all laser optics were mounted on a large axial traverse. Radial planes were measured in different circumferential angles by rotating the nozzle on the jet rig. Figure 1 shows the traverse positioned in an upstream location with the PIV system operational.

The laser pulses were synchronized with the cameras and frame-grabbers using TSI Corporation's Insight (Version 3.2) software and Synchronizer. The Synchronizer controlled the timing of the pulsed light source relative to the CCD camera frame transfer period. PIV image frame pairs, required to produce an instantaneous velocity map, were acquired primarily at a time separation of 2.2 microseconds. This was done to accommodate the expected out of plane motion, instantaneously as high as $150 \mathrm{~m} / \mathrm{s}$, with a light sheet $0.6 \mathrm{~mm}$ thick. Previous experience with PIV in jets showed that out of plane motion was a limiting factor in obtaining accurate results. To test this understanding, limited data points were acquired with 4 and 6 microsecond pulse. The data processed at these time separation showed little difference in their turbulence statistics, but did have regions where the image correlation began to fail, signifying that out of plane motions were becoming important as the time separation become too long. At each location 400 image pairs were recorded by each camera.

The collected PIV image data were processed using a NASA-developed code. The PIVPROC software uses fuzzy logic data validation to ensure that high quality velocity vector maps are obtained ${ }^{3}$. The correlation based processing allows subregion image shifting, asymmetric subregion sizes and multi-pass correlation processing. A grid was constructed, registered on the nozzle lip from the first frame image, so that velocities computed from each image would create a uniform map. Five velocity grid cells overlapped in the radial direction and three in the axial direction. A multipass scheme was employed, using first a 64 by 64 pixel region to determine mean shift of images, followed by a 32 by 32 pixel pass with $50 \%$ overlap between grid cells. The 32 by 32 pixel grid corresponded to a 0.088 inch $(2.24 \mathrm{~mm})$ grid size in physical space.

The procedure for computing statistics from a series of processed PIV image velocity vector maps utilizes several acceptance criteria to qualify vectors and identify and remove incorrect vectors: signal to noise ratios for the image correlation, hard velocity cutoff limits and an Chauvenay criteria procedure for identifying outliers. A relative data 'quality' metric was defined as the number of accepted velocity vectors at a point relative to the total number of frame pairs processed. This field was used to blank out regions of the contour plots where the quality was less than 0.8 ; most regions had a quality metric in the $0.90-0.99$ range.

\section{Test Models}

In the PIV portion of the SFNT2K test covered in this report, three nozzles were measured in detail. All nozzles had bypass ratio 5 and an external plug. These were the baseline (3BB), alternating 12 count chevron $\left(3 \mathrm{~A}_{12} \mathrm{~B}\right)$, and 24 count alternating tabbed nozzle $\left(3 \mathrm{~T}_{24} \mathrm{~B}\right)$. These were chosen because they had the most dramatic and beneficial acoustic and mean flow changes as measured during the 1997 tests.

Model 3BB was the baseline nozzle, being axisymmetric on both core and fan nozzles. This model represented a generic separate flow nozzle such as are flying on medium twin engine commercial transports today. The plug angle is approximately $16^{\circ}$. The core cowl exit diameter is 5.156 inches $(130.9 \mathrm{~mm})$ (cold) and the core cowl external boattail angle is approximately $14^{\circ}$. At cold conditions, the core cowl exit plane is 4.267 inches $(108.4 \mathrm{~mm})$ downstream of the fan nozzle exit plane. The fan nozzle had an exit diameter of 9.70 inches $(246.3 \mathrm{~mm})$. A photo of this model is given in Figure 2a.

Model $3 \mathrm{~A}_{12} \mathrm{~B}$ substituted an alternating chevron trailing edge on the core nozzle for the axisymmetric one of 3BB. Chevrons can be thought of as being cut into the otherwise axisymmetric nozzle to have the baseline throat at the half height of the chevrons. Basic chevrons follow flow lines of baseline nozzle past the throat. The alternating chevron core starts from a flow-aligned chevron design with half of the chevrons being bent into the core stream approximately $4.5^{\circ}$ with a small additional cusp to the chevron. The other half of the chevrons were bent into the fan stream by roughly $8^{\circ}$. More details about the original design philosophy and acoustic performance are given in reference ${ }^{4}$, the report on the 1997 SFNT generated by GEAE, the designers of this nozzle. The result is a core flow with a six-sided 
star-shaped cross-section shortly downstream of the plug. A photograph of the $3 \mathrm{~A}_{12} \mathrm{~B}$ model is given in Figure 2b.

Although its thrust coefficient was reduced by roughly $0.5 \%$ by the addition of the chevron ${ }^{5}$, this nozzle produced roughly $3 \mathrm{~dB}$ suppression at the takeoff power condition. Because of the extreme change in both mean flow profile and far-field noise produced by the alternating chevron design, this model was chosen for detailed PIV measurements.

Model $3 \mathrm{~T}_{24} \mathrm{~B}$ substituted an alternating tab trailing edge on the core nozzle for the axisymmetric one of $3 \mathrm{BB}$. Two aspects of the tab design distinguish it from the chevron design. First, the tabs protrude into the flow from the nominal flow alignment starting with a hard break, not a gradual bend. The tabs make an angle of approximately $45^{\circ}$ with the flow, making a significant blockage of the flow. Second, in alternating the tab pattern, six of the tabs were bent inward, 6 were bent outward at an angle $45^{\circ}$ to the flow, and 12 were left aligned with the flow. This six-count pattern again resulted in a mean core flow with a six-sided star-shaped cross-section shortly downstream of the plug. A photo of the $3 \mathrm{~A}_{12} \mathrm{~B}$ model is given in Figure $2 \mathrm{c}$.

One important note on a significant imperfection in the model system is in order. It was determined after the test that the models had a significant droop, creating a slightly nonsymmetric flow field. The centerbody was found to be angled roughly $1.5^{\circ}$ down, while the core nozzle angled down just less than $1^{\circ}$. This droop affects comparisons of centerline data from these measurements with other data or simulations. Differences between the models are relatively unaffected by this imperfection. Furthermore, it should be noted that the data were acquired on the bottom half of the jet and flipped in the figures to produce positive radial coordinates, so the droop is in the upward direction in the figures.

For the PIV test only one flow condition was used, given in Table 1, representing a take-off power setting of a contemporary subsonic medium to large commercial transport craft. The freejet was run at $\mathrm{M}=0.28$ to simulate flight effects during takeoff. The facility controllers were set to maintain $0.5 \%$ tolerance on core and fan pressures and temperatures. The freejet Mach number was maintained to within $1.5 \%$.

\begin{tabular}{lll}
\hline Stream & NPR & $\mathrm{T}_{\text {total }}\left({ }^{\circ} \mathrm{R}\right)$ \\
\hline Fan & 1.830 & 600 \\
Core & 1.680 & 1500 \\
\hline
\end{tabular}

Table 1. Flow conditions tested.

\section{Nomenclature and Theoretical Framework}

\section{One-point statistics}

Following standard turbulence nomenclature ${ }^{6}$, subdivide the instantaneous velocity vector $\vec{U}$ into time mean and fluctuating parts:

$$
U_{i}(\vec{x}, t)=\overline{U_{i}}(\vec{x})+u_{i}(\vec{x}, t)
$$

where $\bar{U}_{i}(\vec{x})$ is the time average velocity and $\overline{u_{i}{ }^{2}}$ is the variance of velocity. Because data was acquired in radial planes, a cylindrical polar coordinate system was chosen with axial, radial, and polar coordinates in that order:

$$
\vec{x}=\left(x_{1}, x_{2}, x_{3}\right)=(x, r, \theta) ; \vec{u}=\left(u_{1}, u_{2}, u_{3}\right) \text {. }
$$

In this study, measurements were taken in the axial (x) and radial (r) planes and only the axial and radial components of velocity $(\mathrm{u}, \mathrm{v})$ were measured. For comparisons with Reynolds-averaged Navier-Stokes solutions, turbulence is assumed to be axisymmetric about the direction of the mean flow and the turbulent kinetic energy is defined as

$$
T K E=\frac{1}{2}\left(\overline{u_{1}^{2}}+\overline{u_{2}^{2}}+\overline{u_{2}^{2}}\right),
$$

with a local turbulence intensity defined as

$$
\frac{\sqrt{\left({u_{1}^{2}}^{2}+\overline{u_{2}^{2}}+\overline{u_{2}^{2}}\right)}}{\sqrt{\left.{\overline{\left(U_{1}^{2}\right.}}^{2}+{\overline{U_{2}}}^{2}\right)}}=\frac{\sqrt{\overline{u^{2}}}}{\bar{U}} .
$$

\section{Two-point statistics}

Our interest in two-point statistics is driven by aeroacoustic theory. Specifically, most aeroacoustic theory requires knowledge of two-point space-time correlations of the velocity field:

$$
\begin{aligned}
\mathbf{R}_{i j}(\vec{\xi}, \tau, \vec{x}) & =\overline{u_{i}(\vec{x}+\vec{\xi} / 2, t+\tau / 2) u_{j}(\vec{x}-\vec{\xi} / 2, t-\tau / 2)} \\
& =\overline{u_{i} u_{j}^{\prime}}
\end{aligned}
$$

where the prime on $u_{j}$ indicates that the velocity is taken at a point different from $u_{i}$ by a small displacement $\vec{\xi}$ and a time delay $\tau$ about the spatial point $\vec{x}$. In this study we do not have velocities at meaningful time delays other than 0 , and hence we will consider only spatial correlations. $\mathbf{R}(\vec{\xi}, \vec{x})$ has five terms (assuming symmetry) in three spatial dimensions for every point in physical space. Further, since we only have two components of velocity in a plane, we only can compute three of the five components in two dimensions in a plane. 
The correlation is normalized in our data by the reference variances,

$$
\tilde{\mathrm{R}}_{i j}(\vec{\xi}, \vec{x})=\frac{\overline{u_{i} u_{j}{ }^{\prime}}}{\sqrt{\overline{u_{i}^{2} u_{j}^{2}}}} .
$$

As a check, the correlations were also normalized by the local variances, with little difference in the result. This is one indication that the assumption of local homogeneity was justified.

\section{Models for Two-Point Correlations}

Models for two-point correlations have traditionally been developed by assuming a functional form separable in space and time. From the equations of motion certain constraints apply ${ }^{7}$ :

$$
\begin{aligned}
& \overline{u_{i} u_{j}^{\prime}}=R_{i j}(\vec{\xi}) g(\tau) \\
& R_{i j}(\vec{\xi})=\overline{u_{1}^{2}}\left[\left(f+\frac{\xi f^{\prime}}{2}\right) \delta_{i j}-\frac{f^{\prime} \xi_{i} \xi_{j}}{2 \xi}\right], \quad f^{\prime}=\frac{\partial f}{\partial \xi}
\end{aligned}
$$

A popular analytic model for the two-point spatial correlation is the Gaussian form

$$
f(\xi)=e^{\frac{-\pi \xi^{2}}{L^{2}}},
$$

yielding the models

$$
\begin{aligned}
& R_{11}(\xi)=\overline{u_{1}^{2}}\left(1-\frac{\pi \xi_{2}^{2}+\pi \xi_{3}^{2}}{L^{2}}\right) e^{\frac{-\pi \xi^{2}}{L^{2}}} ; \\
& R_{22}(\xi)=\overline{u_{1}^{2}}\left(1-\frac{\pi \xi_{1}^{2}+\pi \xi_{3}^{2}}{L^{2}}\right) e^{\frac{-\pi \xi^{2}}{L^{2}}}
\end{aligned}
$$

When compared against current data, the Gaussian form seems a poor fit-the zero derivative of the correlation at $\xi=0$ is not obvious and the curvature there is very small given the relatively large Reynolds number. Modifying the model above by changing the power of the exponent, setting

$$
f(\xi)=e^{\frac{-\pi \xi}{L}}
$$

produces a more satisfying fit to the data.

Another part of the popular model that does not agree with data is the assumption of isotropy. Indeed, it has been found that the two cross-stream turbulence intensities are nearly equal, but are less than the axial turbulence intensity. For this reason an axisymmetric turbulence model is examined. Following the derivation $^{8}$ and substituting a single-power exponential form for the Gaussian form, the two-point spatial correlation model is given by

$$
\begin{aligned}
& R_{11}(\vec{\xi})=-2 Q_{1}\left(1-\mathrm{X}_{2}-\mathrm{X}_{3}\right) \\
& R_{22}(\vec{\xi})=\left(2+\pi^{2} \mathrm{X}_{3}^{2}\right) \frac{Q_{2}}{2} \\
& +\left(8 \gamma+\pi^{2}\left(\mathrm{X}_{1}^{2}\left(2 \gamma-4 \gamma \Delta^{2}+\pi\left(\begin{array}{l}
\pi \gamma\left(-1+\Delta^{2}\right)^{2} \\
+\left(-1+\Delta^{2}\right) K_{2}
\end{array}\right) \mathrm{X}_{3}{ }^{2}\right)\right.\right. \\
& \left.\left.+\mathrm{X}_{3}^{2}\left(-4 \gamma+\pi \Delta^{2} K_{2}\left(\mathrm{X}_{2}{ }^{2}+\mathrm{X}_{3}^{2}\right)\right)\right)\right) \frac{Q_{1}}{4 \gamma}
\end{aligned}
$$

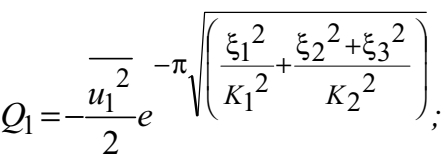

$$
\begin{aligned}
& Q_{2}=\left(\overline{u_{2}^{2}}-\overline{u_{1}^{2}}\right) e^{-\pi \sqrt{\left(\frac{\xi_{1}^{2}}{K_{1}^{2}}+\frac{\xi_{2}^{2}+\xi_{3}^{2}}{K_{2}^{2}}\right)}} \\
& X_{i}=\frac{\sqrt{\pi}}{K_{2} \gamma} \xi_{i} ; \Delta=\frac{K_{2}}{K_{1}} ; \gamma^{2}=\Delta^{2} \xi_{1}^{2}+\xi_{2}^{2}+\xi_{3}^{2}
\end{aligned}
$$

This is the functional form to which the data was fitted and to which it had the best fit.

\section{Integral Lengthscales}

In modeling the two-point spatial velocity correlation, it is often assumed that there is some displacement over which the velocities become uncorrelated. One definition of this is the integral lengthscale $L$,

$$
L_{i k}(\vec{x})=\int_{0}^{\infty} \tilde{R}_{i i}\left(\xi_{k}, \vec{x}\right) d \xi_{k},
$$

which happens to nicely match the scaling exponent $L$ of the Gaussian form. One can still apply the same definition for lengthscale $L$ to cases where the flow is not isotropic. However, computing this integral with discrete data over a finite range, such as is obtained in the present experiments, does introduce a significant uncertainty in the measure of $L$. Fitting a reasonable functional form to the data and integrating it yields a statistic independent of interrogation region.

One nice property about integral lengthscales is the ratio of $L_{i i} / L_{k i}=2, i \neq k$ for isotropic turbulence. Even in axisymmetric turbulence, the ratio still holds when $i$ $=2$ or 3 and $\mathrm{k}=1$. That is, when the separation vector is cross-stream, the correlation of axial velocity should decay at twice the rate of the velocity component in the separation direction. 


\section{Presentation and Discussion of Results}

Many of the results will be presented as contour plots of the jet plume. In these plots the 3BB nozzle is shown on top, while the $3 \mathrm{~A}_{12} \mathrm{~B}$ is shown on the left and the $3 \mathrm{~T}_{24} \mathrm{~B}$ nozzle on the right. For these last two nozzles, are presented in 3 radial planes clocked at (from the topmost figure) $30^{\circ}, 15^{\circ}$, and $0^{\circ}$ from the outward-bent chevron or tab. Since the flows all had 6-fold symmetry in their cross-section, the $30^{\circ}$ sector represents a repeating pie segment of the flow for the entire cross-section. Previous cross-sections taken with temperature and pressure rakes assured that the flow was satisfactorily symmetric.

\section{Mean velocities}

First, consider axial mean velocity, given in Figure 3 for the three nozzles. The axisymmetric flow field has an extended region, out to $2 \mathrm{~m}$, or 8 fan diameters, with velocities above $450 \mathrm{~m} / \mathrm{s}$. In contrast, the two enhanced mixer nozzles produce flow fields where the mean velocity is below $400 \mathrm{~ms}$ within $1.5 \mathrm{~m}$, or 6 fan diameters. While subtle differences exist between the two mixer nozzle flow fields, they are very similar, with both producing strong spread and a high speed ejection in the $0^{\circ}$ plane. The increased mixing and subsequent reduction in high mean velocities is obvious.

Looking at mean radial velocities in Figure 4, we notice the dramatic radially outward core velocities just downstream of the plug in the $0^{\circ}$ plane of the $3 \mathrm{~A}_{12} \mathrm{~B}$ and $3 \mathrm{~T}_{24} \mathrm{~B}$ flow fields. Again, the differences between the two mixers is small, both peaking around $75 \mathrm{~m} / \mathrm{s}$, with the $3 \mathrm{~A}_{12} \mathrm{~B}$ nozzle having just slightly stronger radial outflow than the $3 \mathrm{~T}_{24} \mathrm{~B}$. There is some compensating inward flow in the $30^{\circ}$ plane where again the radial flow of the $3 \mathrm{~A}_{12} \mathrm{~B}$ nozzle is slightly stronger.

\section{$\underline{\text { Turbulence }}$}

In separate flow nozzles three main mixing regions are traditionally identified: the inner shear layer between core and fan flows, the outer shear layer between the fan and ambient flows, and the jet mixing region, located roughly where an equivalent single-flow jet would have peak turbulence. The baseline nozzle flow has peak turbulent kinetic energy (TKE) between 1 and $2 \mathrm{~m}$ (4-8 fan diameters) downstream of the fan exit, e.g., the jet mixing region, as shown in Figure 5. The peak TKE is approximately $3500 \mathrm{~m}^{2} / \mathrm{s}^{2}$ but there is a large extent where the TKE is greater than $3000 \mathrm{~m}^{2} / \mathrm{s}^{2}$. In the $3 \mathrm{~A}_{12} \mathrm{~B}$ nozzle the TKE in the jet mixing region is greatly reduced-from $3500 \mathrm{~m}^{2} / \mathrm{s}^{2}$ down to $2500 \mathrm{~m}^{2} / \mathrm{s}^{2}$. Alternating chevrons create considerable turbulence at $0^{\circ}$ azimuth (downstream of the outward chevron) around $0.6 \mathrm{~m}$, of 2.4 fan diameters downstream in the fan/core shear layer where the core flow pushes outward through the fan flow and produces a strong shear as it nearly contacts the ambient fluid. In fact, this is the strongest region of turbulence in this jet, with TKE reaching over $3000 \mathrm{~m}^{2} / \mathrm{s}^{2}$. The $3 \mathrm{~T}_{24} \mathrm{~B}$ nozzle does not have quite as much reduction in the jet mixing region downstream, but also does not produce as much TKE in the region near $0.6 \mathrm{~m}$.

The logical question arising from Figure 5 is, "Have the chevrons actually modified the turbulence such that turbulence intensity is reduced?" Figure 6 shows that in fact the local intensity $\sqrt{\overline{u^{2}}} / \bar{U}$ has been redistributed, but that the peak local intensity in the jet mixing region is pretty much the same as it was in the baseline case. The main effect of the chevrons is to increase the turbulence intensity upstream of the jet mixing region. Not shown are the figures for turbulence intensity as normalized by the jet exit velocity. These fields look like those of Figure 5 and in the case of the 3BB nozzle peak around $14 \%$.

The ratio of radial to axial turbulence $\overline{u_{2}^{2}} / \overline{u_{1}^{2}}$ is of interest in jet noise theory, and is shown in Figure 7. In these plots the turbulent kinetic energy has been used to highlight the regions where acoustic sources are strong $\left(\mathrm{TKE}>500 \mathrm{~m}^{2} / \mathrm{s}^{2}\right)$. This ratio is different between the enhanced mixing nozzles and the baseline nozzle. The baseline nozzle has a ratio of $0.3-0.35$ in the jet mixing region, while the enhanced mixing nozzles have a ratio of $0.45-0.55$ in this region. Thus, besides reducing the turbulence in the jet mixing region of the jet plume, the mixing enhancement devices also make the turbulence more isotropic.

\section{Integral Lengthscales}

Two-point correlations were calculated from the velocity maps, and integral lengthscales were computed from these correlations. In its most basic definition, the integral lengthscale is determined by integrating the twopoint correlation about its reference point, an approach that can be inaccurate both by assumption of homogeneity and lack of enough displacement to reach convergence. The insensitivity of the lengthscale measurement to whether the two-point correlations were normalized by reference point variances or local variances indicated that the lengthscale measurement is not strongly affected by the lack of homogeneity in the radial direction. To mitigate the latter error, two-point correlations were only computed about reference points in the axial center of the PIV velocity maps, and integrals were computed from fitted functions. Specifically, the correlations were fitted using the axisymmetric, singlepower exponential forms given in equation (9) so that the integrals would not be truncated by the limited extent of the displacement.

Obviously, when using the fitted curves to compute the integral lengthscales it is crucial that the appropriateness of the model be examined. To illustrate the fidelity with which the proposed model fit the two-point 
correlation data, a representative set of curves is given in Figure 8. Two components of the correlation tensor $R_{i i}$, are shown plotted on principle axes of the displacement vector $\xi_{k}$. Both data and curve fits using Gaussian (equation 7) and single-power exponential (equation 9) forms of the two-point correlation model are given. In all cases the single-power exponent model provides the best fit and is a reasonable approximation of the experimental data. Quantitatively, the variance of the fits were 0.01 or less $\left(\mathrm{R}^{2}>0.99\right)$ for virtually the entire plume in all nozzles, with the radial correlations being especially well fit. Hence, the integral values calculated from the fitted curves will be shown here.

The axial lengthscale from axial velocity, $L_{11}$, is plotted for all models in Figure 9. Lengthscale values start around $0.005 \mathrm{~m}$ in the inner and outer shear layers and reaching a value of almost $0.1 \mathrm{~m}$ by the end of the measurement region $2.3 \mathrm{~m}$ downstream. Because of the mesh spacing upon which velocities were measured, there is a lower bound on lengthscale of approximately $0.003 \mathrm{~m}$.

Within the experimental uncertainty obvious in the noise of the plots, there is very little difference between $L_{11}$ for the $3 \mathrm{BB}$ and enhanced mixing nozzles, or between the different planes of the enhanced mixing nozzle plumes. So while the mixing enhancement devices do alter the turbulence intensity and ratio of turbulence intensities, they do not seem to change the lengthscale distribution appreciably.

To compare the various lengthscales in a plume, $L_{11}, L_{12}, L_{21}, L_{22}$ are plotted in Figure 10 for the $3 \mathrm{BB}$ nozzle. Not shown are the other lengthscales for the enhanced mixing nozzles, which are similar to that of 3BB. Carefully note the legend for the contour levels in the Figure. The main difference one observes between the plots within Figure 10 is the large integral lengthscales of the radial velocities near the jet axis, both in separations in $\mathrm{x}$ and in $\mathrm{y}$. The cause for this is not known, but might be related to a suspected separation from the end of the plug, the wake being well correlated for a long distance downstream.

The ratio of lengthscales, e.g. $L_{11} / L_{21}$ and $L_{22} / L_{12}$, is a value of interest in jet noise modeling. When the ratios of lengthscales are calculated from the experimental results and plotted, as they are in Figure 11 and Figure 12, the fields are found not to be very uniform due to experimental uncertainty. This is especially true on the low-speed edge of the jet and the aforementioned anomalies near the centerline just downstream of the plug. In the estimate from the axial lengthscales, $L_{11} / L_{21}$ (Figure 11), the lengthscale ratio is roughly 2 throughout the jet mixing region. In the estimate from the radial lengthscales, $L_{22} / L_{12}$ (Figure 12), the ratio is fairly uniform at a value of around 1. However, one cannot simply use these values as a global parameter in the prediction of jet noise due to the fact that the different nozzles have different distributions of TKE. For example, the 3A12B nozzle has significant turbulence around $0.6 \mathrm{~m}$ where the lengthscale ratio $L_{11} / L_{21}$ is closer to 1 than to 2 .

As pointed out above, in both isotropic and axisymmetric turbulence, the ratio $L_{22} / L_{12}$ should be exactly 2 , a result clearly at variance with the present data, where the value is closer to 1 . This discrepancy will need to be investigated in future work and perhaps a more complicated turbulence model developed to match these observations.

\section{Summary of Findings}

\section{Main findings:}

- Mean velocity of the jet plume was lowered nearly equally by both the chevron and tab mixing enhancement devices.

- Turbulent kinetic energy in the jet mixing region was lowered by both the chevron and tab mixing enhancement devices. Turbulence in the first two fan diameters was increased in the fan/core shear layer, especially in the radial plane including the outward chevron or tab. The chevron nozzle had the greatest increase in turbulence in the fan/core shear layer.

- Ratio of axial to radial components of turbulence was changed by the mixing enhancement devices, becoming more isotropic.

- Integral lengthscales in the jet plume are not significantly affected by the mixing enhancement devices, varying by roughly two orders of magnitude over the first 10 fan diameters of the flow. However, the change in TKE produced by the chevrons means that peak turbulence regions had different lengthscales in the mixing enhancement nozzles.

- Ratios of integral lengthscales do not agree with isotropic or axisymmetric turbulence models, especially for transverse separations.

\section{References}

${ }^{1}$ Saiyed, N., ed., 2000, "Separate Flow Nozzle Test Status Meeting," NASA/CP-2000-210524.

${ }^{2}$ Long, M.J., 1992, "Experimental Investigation of an Ejector-Powered Free-Jet Facility,” NASA TM-105868.

${ }^{3}$ Wernet, M.P., 1999, "Fuzzy Logic Enhanced Digital PIV Processing Software," NASA/TM-1999-209274. 
${ }^{4}$ Janardan, B.A., Hoff, G.E., Barter, J.W., Martens, S., Gleibe, P.R., Mengle, V., and Dalton, W.N., 2000, "AST Critical Propulsion and Noise Reduction Technologies for Future Commercial Subsonic Engines Separate-Flow Exhaust System Noise Reduction Concept Evaluation," NASA/CR—2000-210039.

5 Saiyed, N., Mikkelsen, K.L., and Bridges, J., 2000, "Acoustics and Thrust of Separate-Flow Exhaust
Nozzles With Mixing Devices for High-Bypass-Ratio Engines," NASA TM 2000-209948.

${ }^{6}$ Bradshaw, P, ed., 1978, Topics in Applied Physics: Turbulence, Springer-Verlag.

${ }^{7}$ Hinze, J.O., 1951, Turbulence: An Introduction to its Mechanism and Theory, McGraw-Hill, p. 54.

${ }^{8}$ Khavaran, A. 1999, "On the role of anisotropy in turbulent mixing noise," AIAAJ 37.
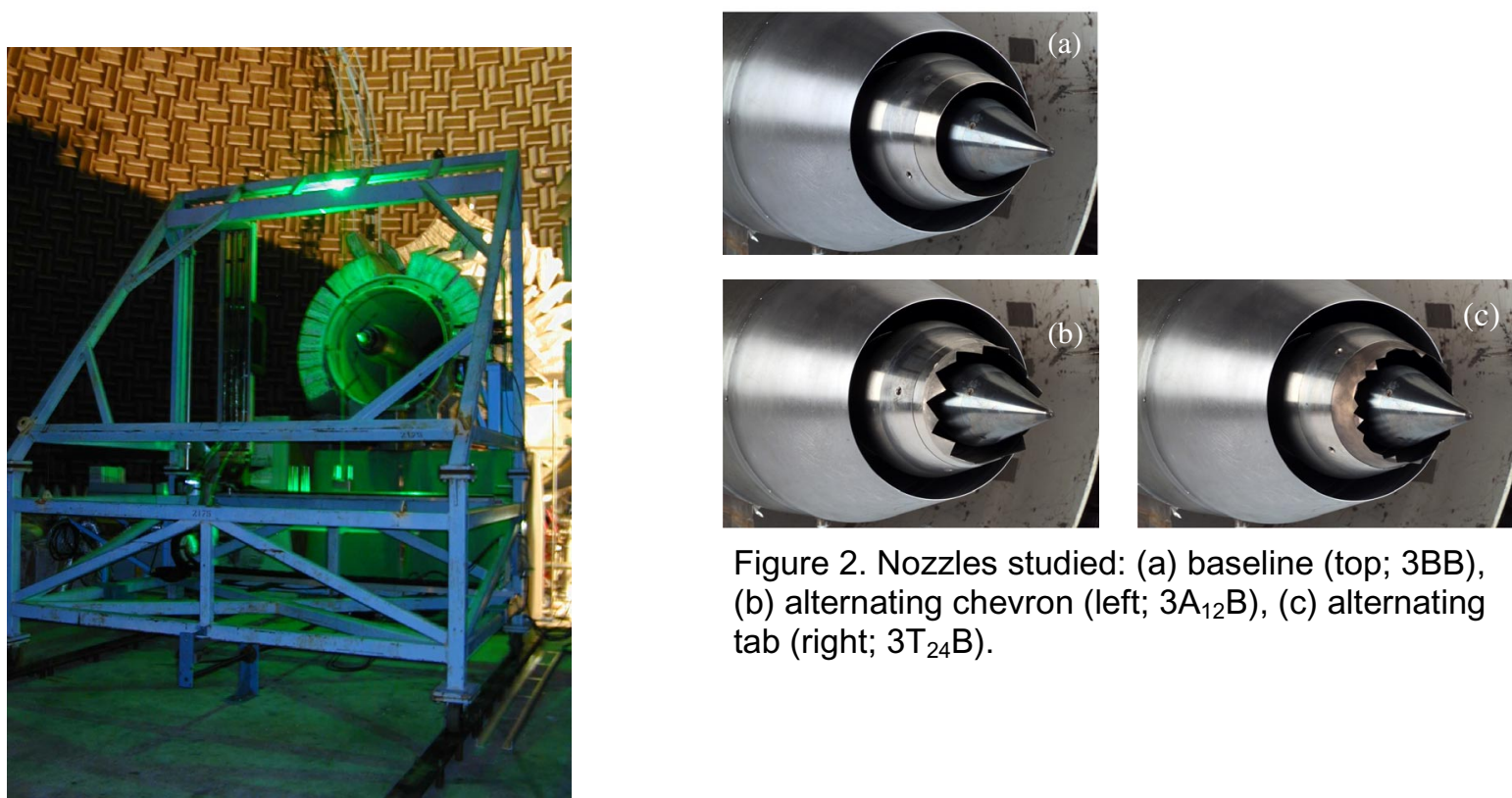

Figure 2. Nozzles studied: (a) baseline (top; 3BB), (b) alternating chevron (left; $3 \mathrm{~A}_{12} \mathrm{~B}$ ), (c) alternating tab (right; $3 \mathrm{~T}_{24} \mathrm{~B}$ ).

Figure 1. PIV operating in AAPL.
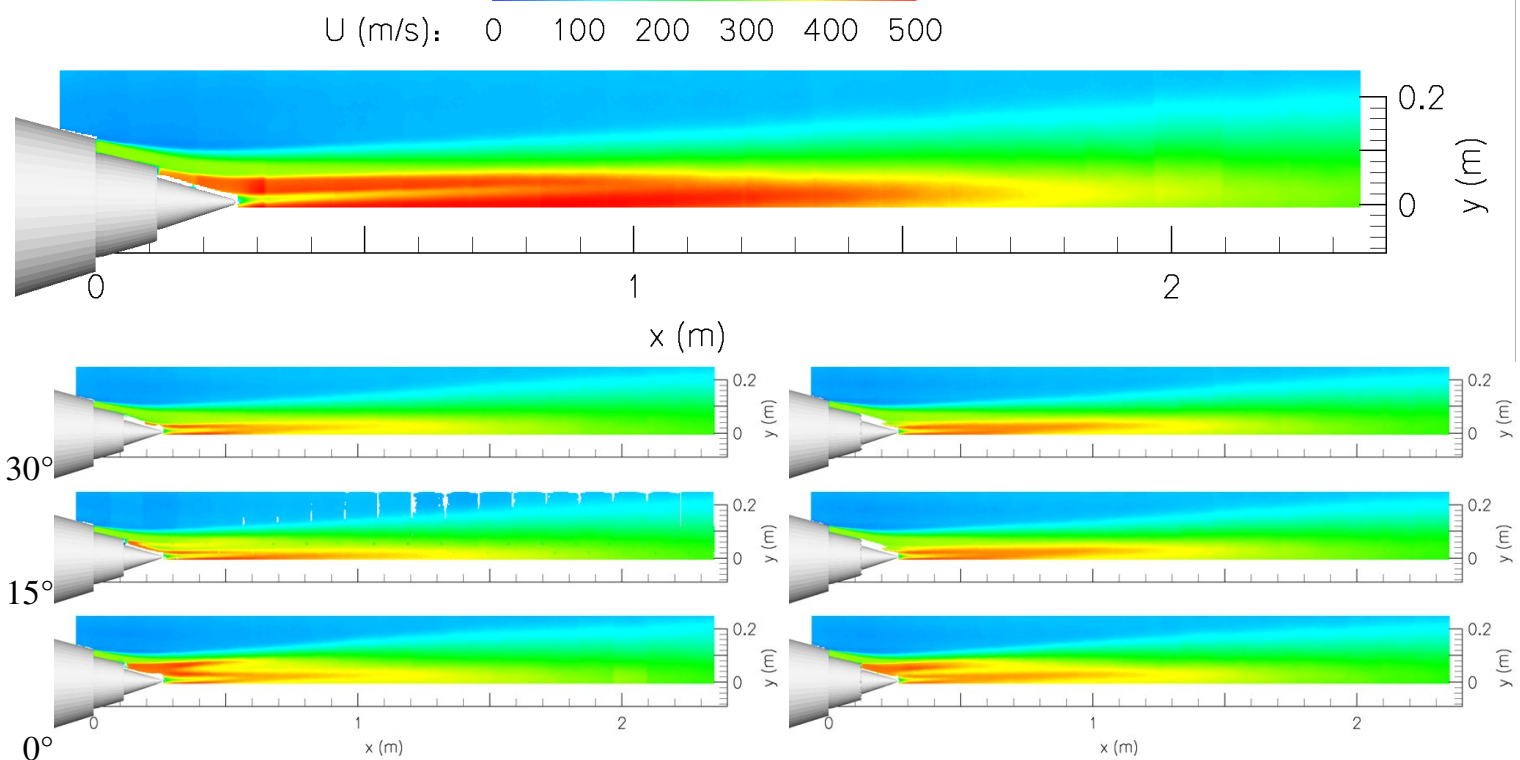

Figure $3 \bar{U}_{1}$ for $3 \mathrm{BB}$ (top), $3 \mathrm{~A}_{12} \mathrm{~B}$ (left), and $3 \mathrm{~T}_{24} \mathrm{~B}$ (right). Three plots for $3 \mathrm{~A}_{12} \mathrm{~B}$ and $3 \mathrm{~T}_{24} \mathrm{~B}$ are for planes at angles of $0^{\circ}, 15^{\circ}$, and $30^{\circ}$ respectively from an inward directed chevron or tab. 


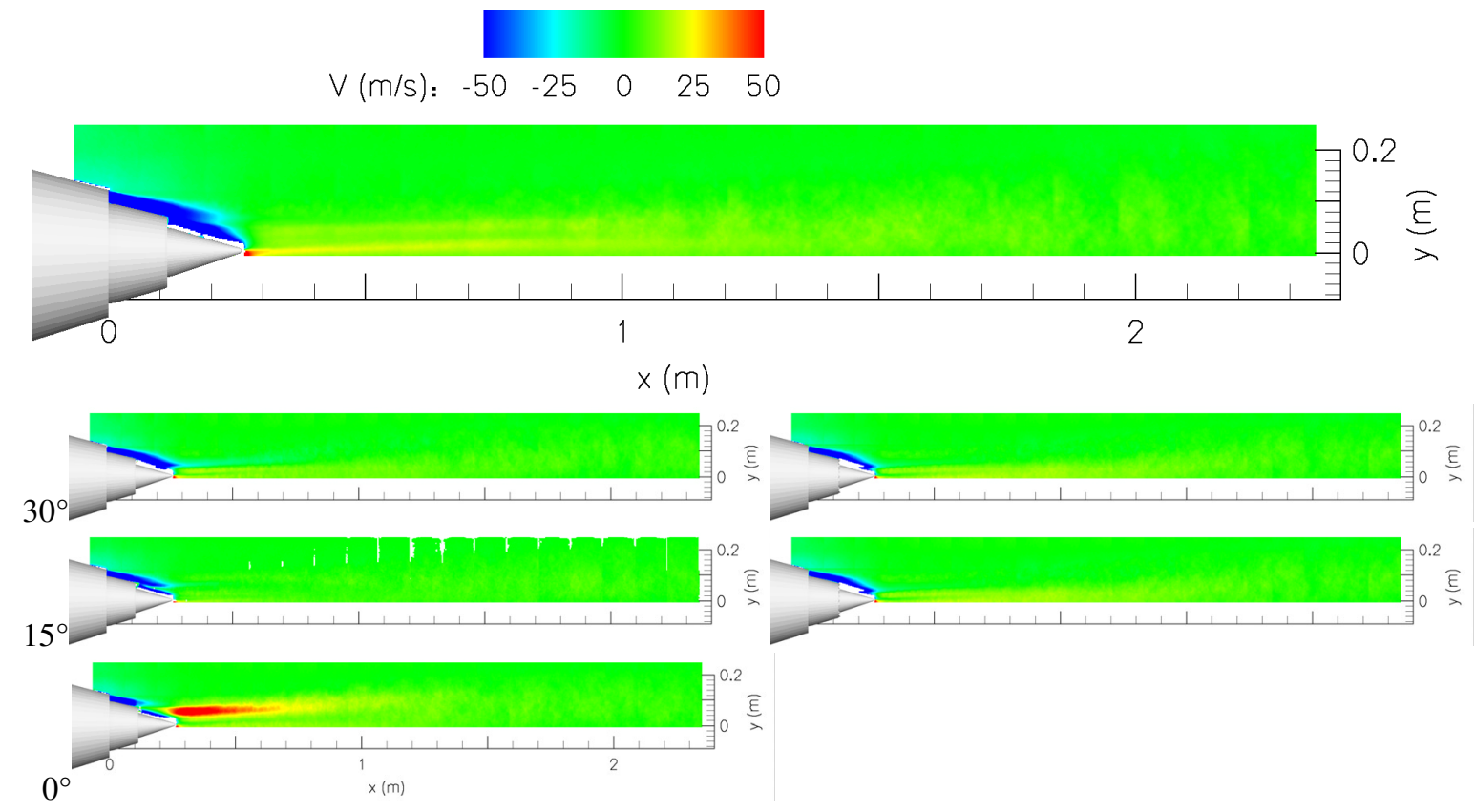

Figure $4 \overline{U_{2}}$ for $3 \mathrm{BB}$ (top), $3 \mathrm{~A}_{12} \mathrm{~B}$ (left), and $3 \mathrm{~T}_{24} \mathrm{~B}$ (right).

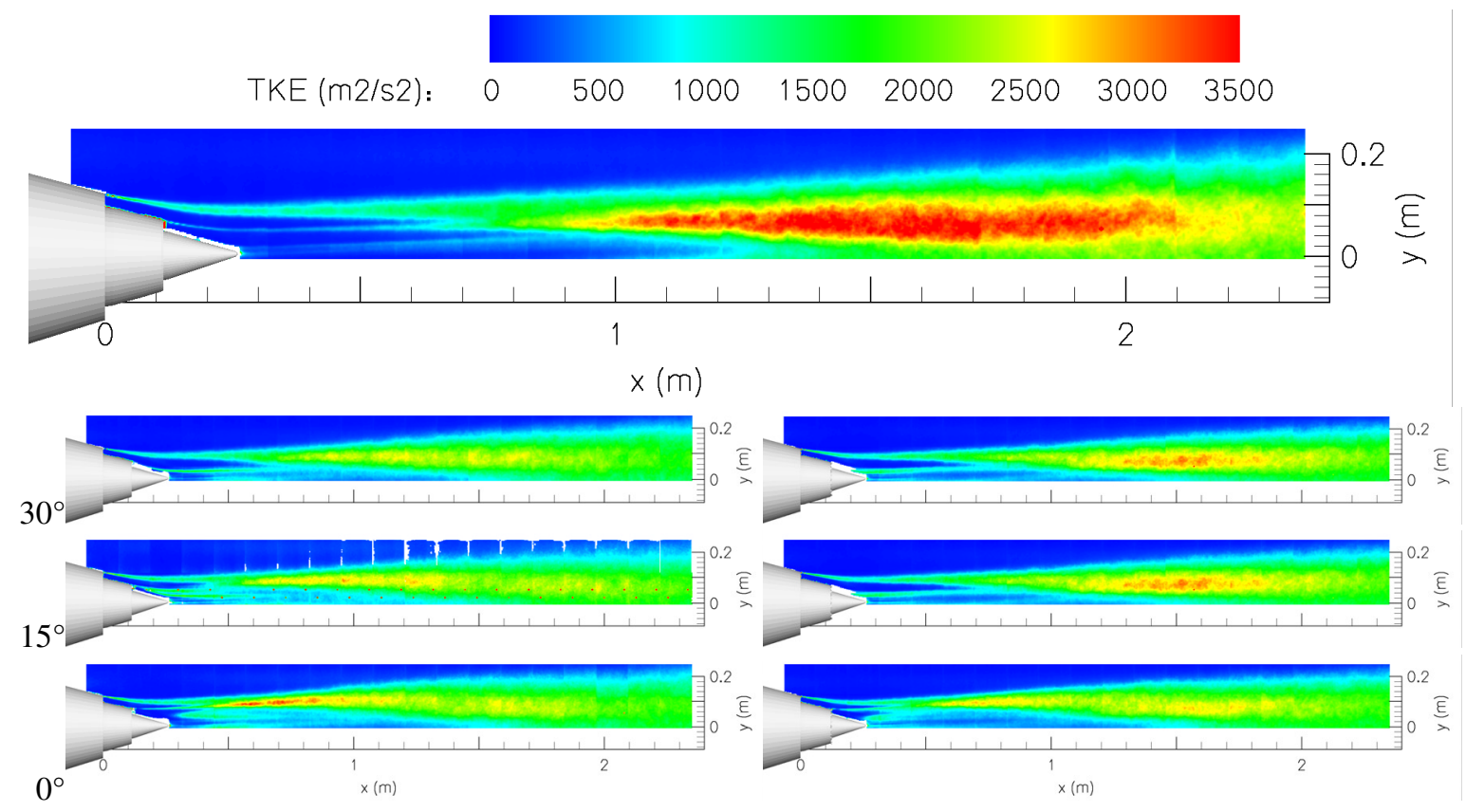

Figure 5 Turbulent kinetic energy (TKE) for 3BB (top), $3 \mathrm{~A}_{12} \mathrm{~B}$ (left), and $3 \mathrm{~T}_{24} \mathrm{~B}$ (right). 


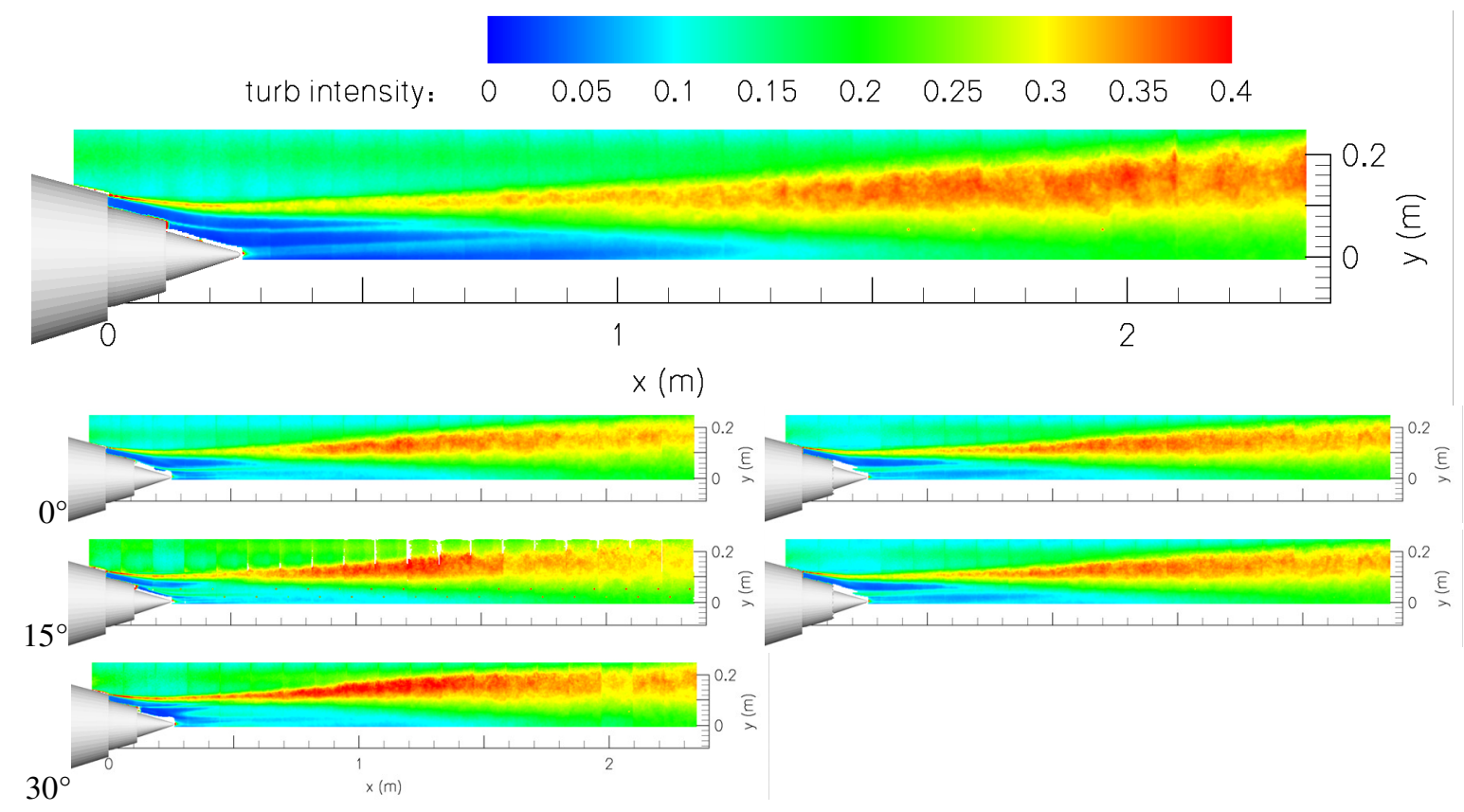

Figure 6 Local turbulence intensity $\sqrt{u^{2}} / \bar{U}$ for $3 \mathrm{BB}$ (top), $3 \mathrm{~A}_{12} \mathrm{~B}$ (left), and $3 \mathrm{~T}_{24} \mathrm{~B}$ (right).
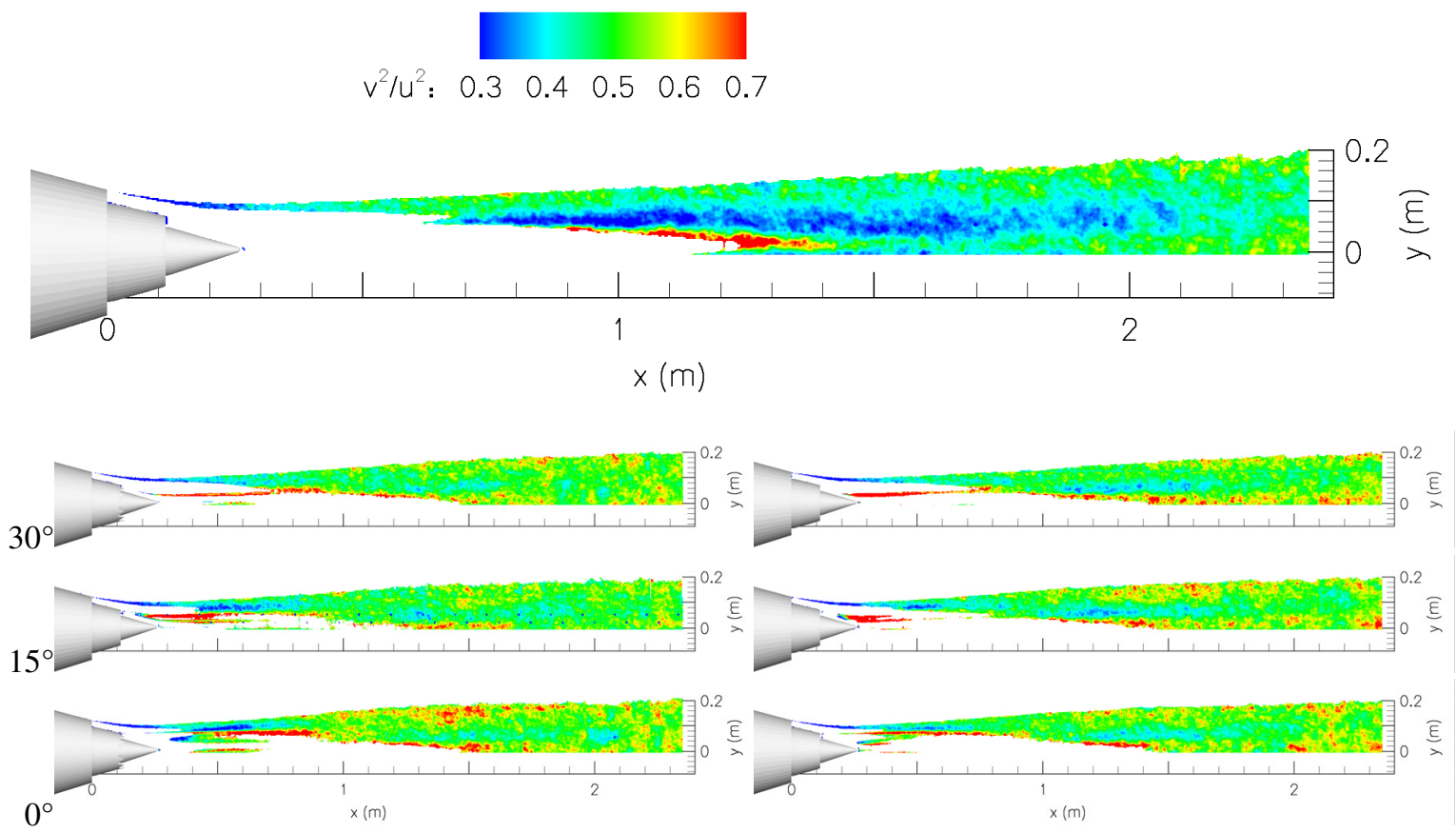

Figure 7 Ratio of turbulence components $\overline{u_{2}^{2}} / \overline{u_{1}^{2}}$ for $3 \mathrm{BB}$ (top), $3 \mathrm{~A}_{12} \mathrm{~B}$ (left), and $3 \mathrm{~T}_{24} \mathrm{~B}$ (right). Only regions where turbulent kinetic energy is greater than $500 \mathrm{~m}^{2} / \mathrm{s}^{2}$ shown. 


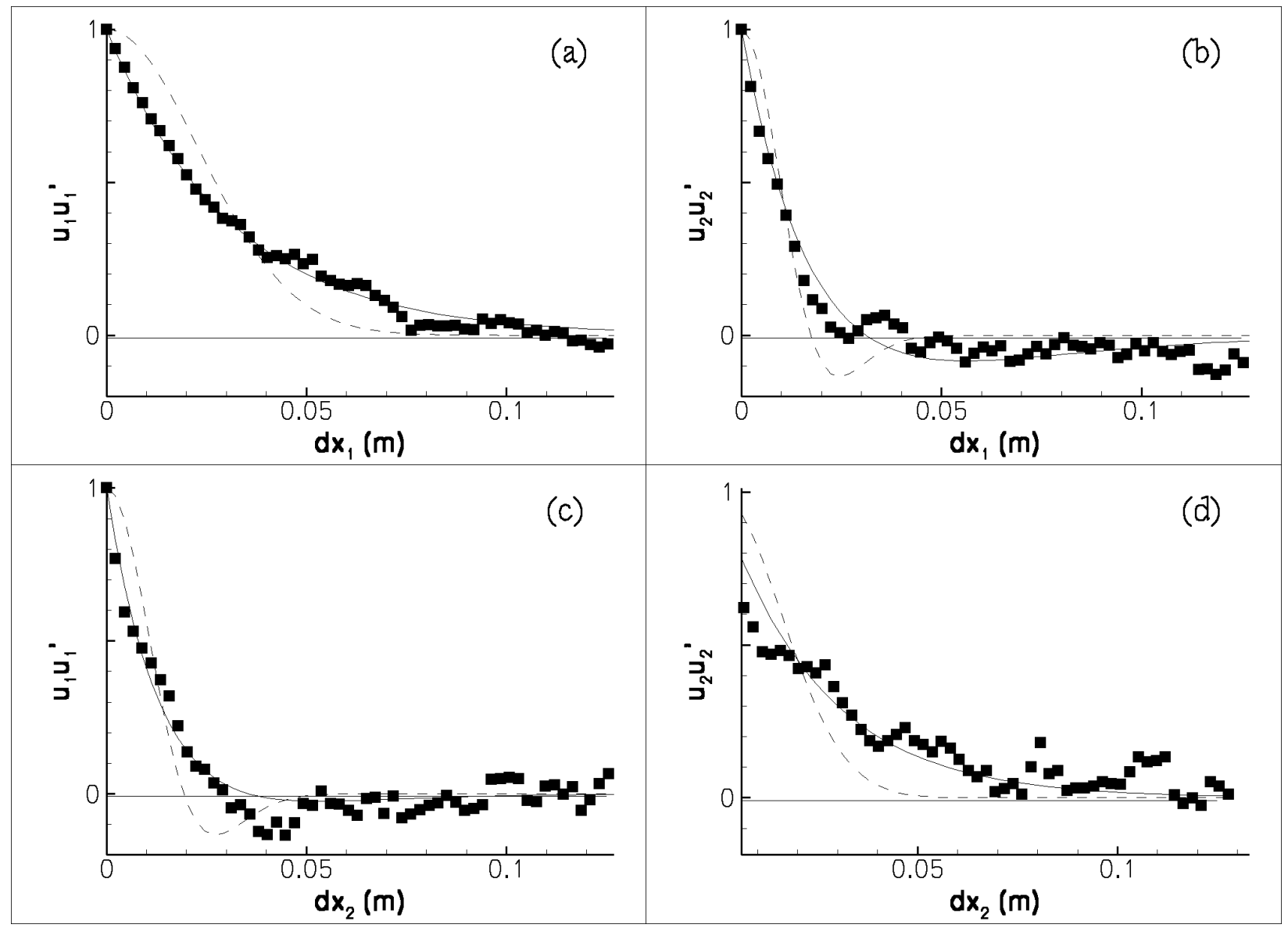

Figure 8. Comparisons of second-order (Gaussian; - - -) vs first-order exponent (-) forms of correlation model with data. $(a) R_{11}\left(\xi_{1}\right),(b) R_{22}\left(\xi_{1}\right),(c) R_{11}\left(\xi_{2}\right),(d) R_{22}\left(\xi_{2}\right)$. Reference point: $\mathrm{x}=0.76 \mathrm{~m}, \mathrm{y}=0.1 \mathrm{~m}$.

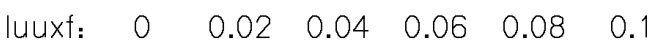

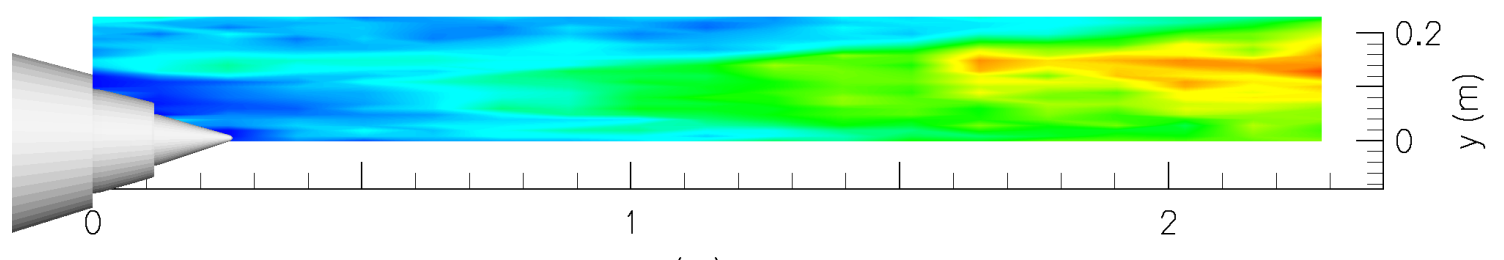

$x(m)$

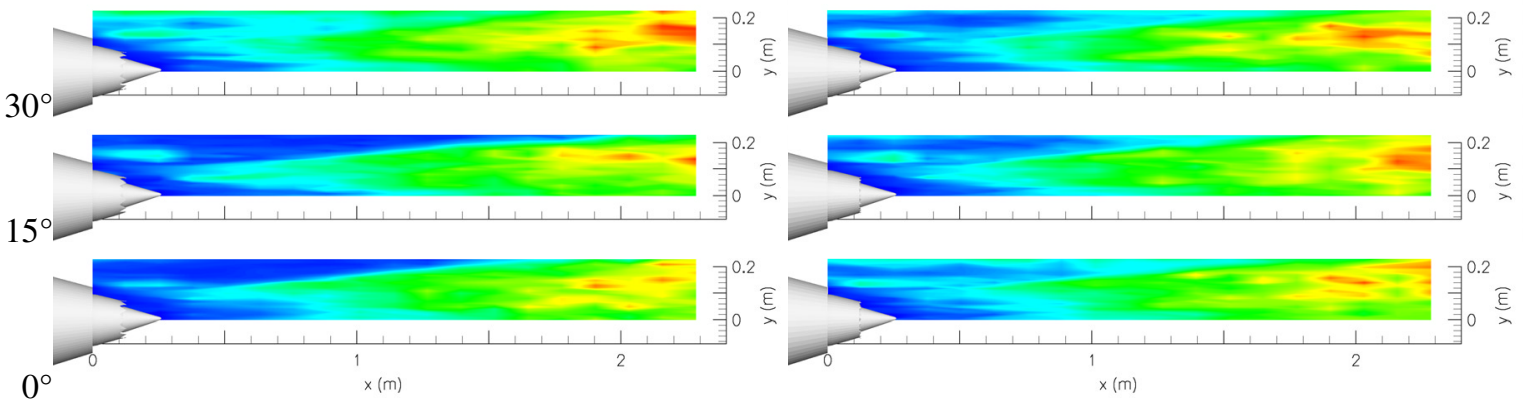

Figure 9 Integral lengthscale $L_{11}$ for $3 \mathrm{BB}$ (top), $3 \mathrm{~A}_{12} \mathrm{~B}$ (left), and $3 \mathrm{~T}_{24} \mathrm{~B}$ (right). 


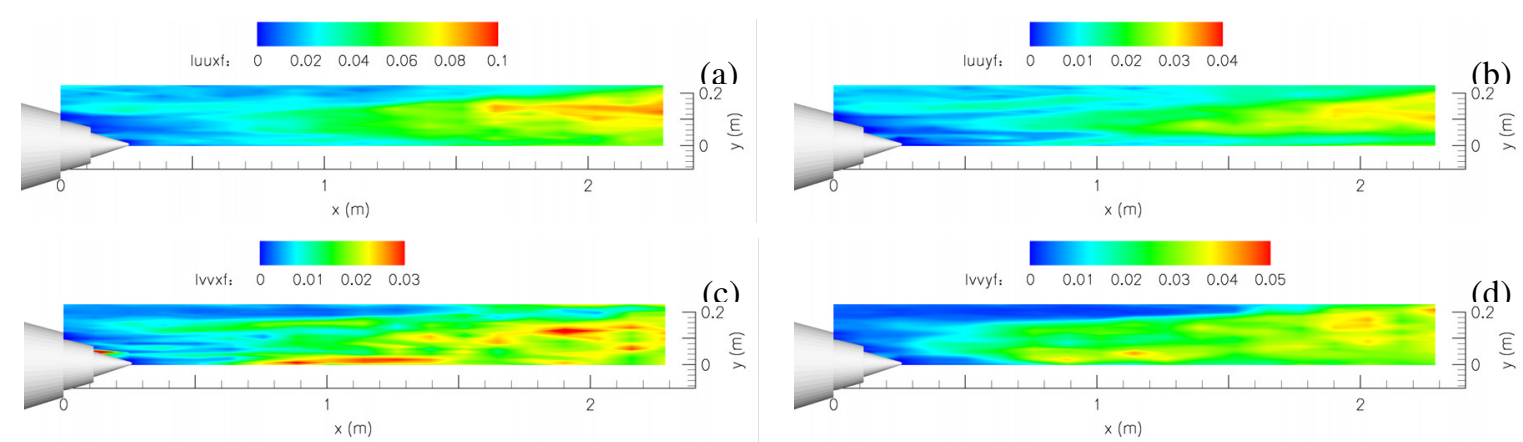

Figure 10 Integral lengthscales $(a) L_{11},(b) L_{12},(c) L_{21},(d) L_{22}$ for 3BB.

IRx: $\begin{array}{lllll}1 & 1.5 & 2 & 2.5 & 3\end{array}$
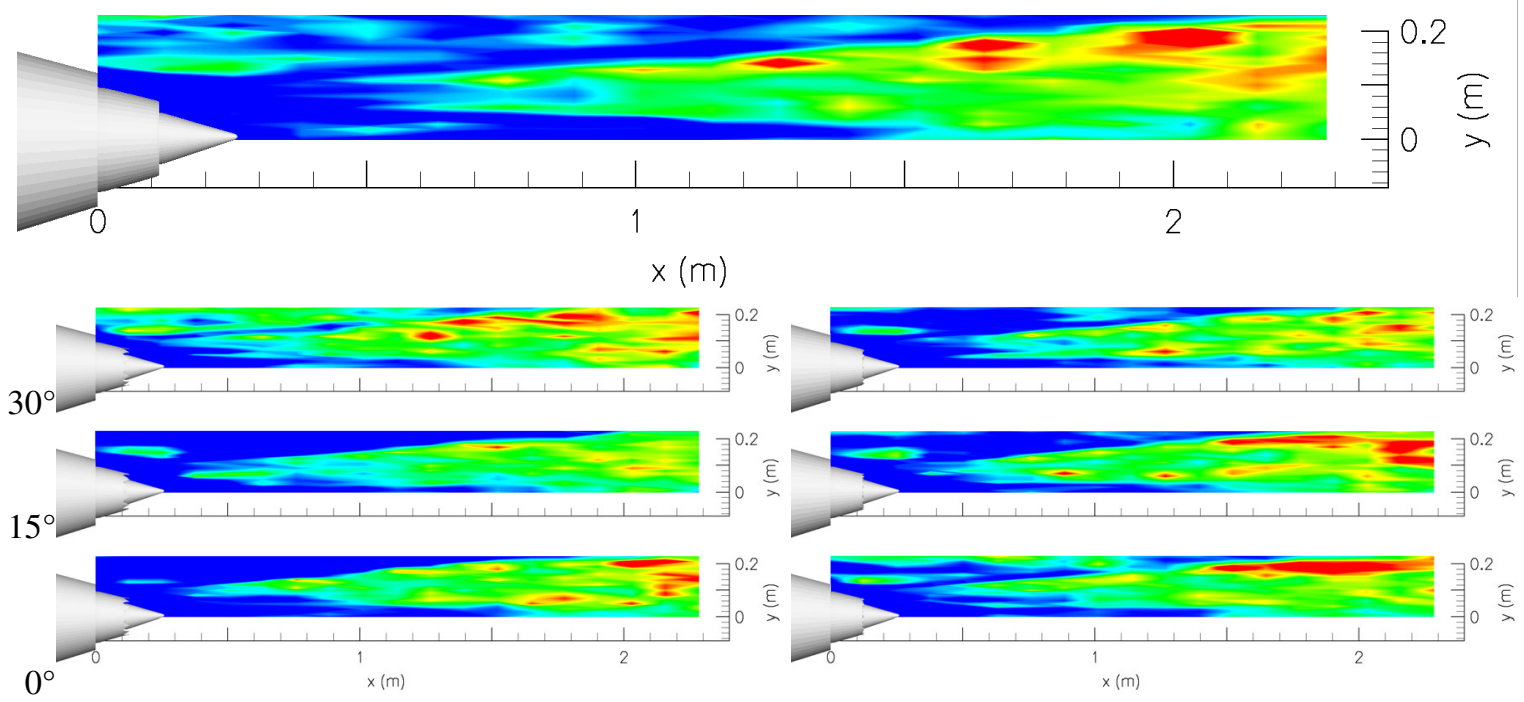

Figure 11 Ratio of axial lengthscales, $L_{11} / L_{21}$, for $3 \mathrm{BB}$ (top), $3 \mathrm{~A}_{12} \mathrm{~B}$ (left), and $3 \mathrm{~T}_{24} \mathrm{~B}$ (right).

IRy: $\quad 0.5 \quad 0.75 \quad 1 \quad 1.25 \quad 1.5$

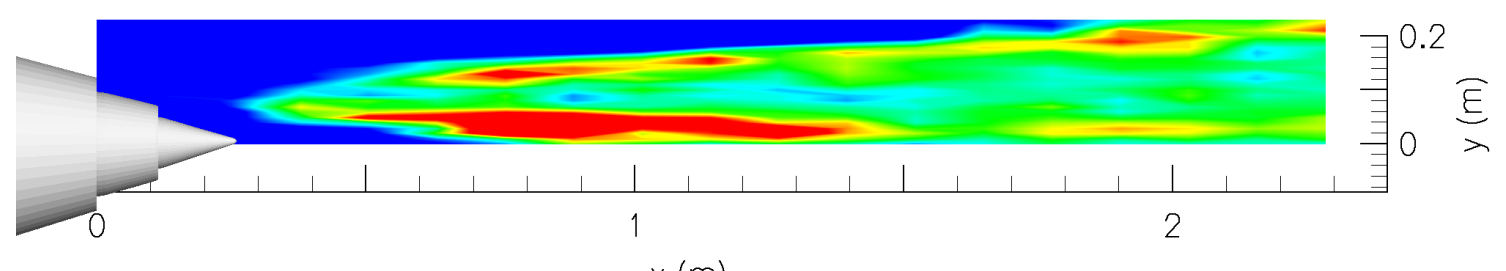

$x(m)$

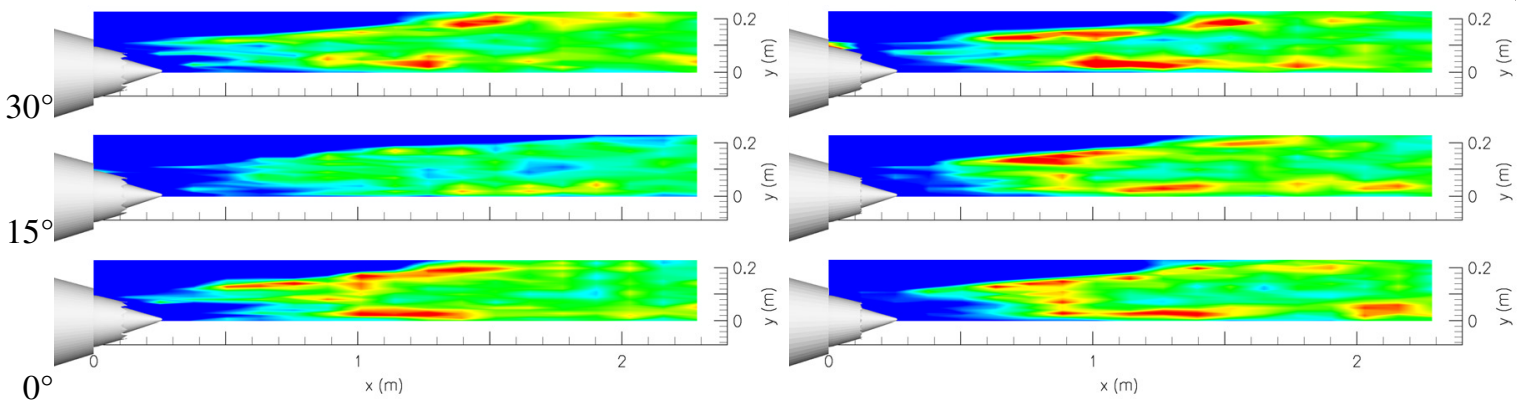

Figure 12 Ratio of radial lengthscales, $L_{22} / L_{12}$, for $3 \mathrm{BB}$ (top), $3 \mathrm{~A}_{12} \mathrm{~B}$ (left), and $3 \mathrm{~T}_{24} \mathrm{~B}$ (right). 
Public reporting burden for this collection of information is estimated to average 1 hour per response, including the time for reviewing instructions, searching existing data sources, gathering and maintaining the data needed, and completing and reviewing the collection of information. Send comments regarding this burden estimate or any other aspect of this collection of information, including suggestions for reducing this burden, to Washington Headquarters Services, Directorate for Information Operations and Reports, 1215 Jefferson Davis Highway, Suite 1204, Arlington, VA 22202-4302, and to the Office of Management and Budget, Paperwork Reduction Project (0704-0188), Washington, DC 20503.

\begin{tabular}{|l|l|l|}
\hline 1. AGENCY USE ONLY (Leave blank) & $\begin{array}{c}\text { 2. REPORT DATE } \\
\text { June } 2002\end{array}$ & $\begin{array}{r}\text { 3. REPORT TYPE AND DATES COVERED } \\
\text { Technical Memorandum }\end{array}$ \\
\hline
\end{tabular}

4. TITLE AND SUBTITLE

5. FUNDING NUMBERS

Turbulence Measurements of Separate Flow Nozzles With Mixing

Enhancement Features

6. AUTHOR(S)

WU-781-30-12-00

James Bridges and Mark P. Wernet

7. PERFORMING ORGANIZATION NAME(S) AND ADDRESS(ES)

National Aeronautics and Space Administration

John H. Glenn Research Center at Lewis Field

Cleveland, Ohio 44135-3191

8. PERFORMING ORGANIZATION

REPORT NUMBER

E-13376

9. SPONSORING/MONITORING AGENCY NAME(S) AND ADDRESS(ES)

10. SPONSORING/MONITORING

AGENCY REPORT NUMBER

National Aeronautics and Space Administration

Washington, DC 20546-0001

NASA TM-2002-211592

AIAA-2002-2484

\section{SUPPLEMENTARY NOTES}

Prepared for the Eighth Aeroacoustics Conference cosponsored by the American Institute of Aeronautics and Astronautics and the Confederation of European Aerospace Societies, Breckenridge, Colorado, June 17-19, 2002. Responsible person, James Bridges, organization code 5940, 216-433-2693.

12a. DISTRIBUTION/AVAILABILITY STATEMENT

12b. DISTRIBUTION CODE

Unclassified - Unlimited

Subject Categories: 07 and 34

Distribution: Nonstandard

Available electronically at http://gltrs.grc.nasa.gov/GLTRS

This publication is available from the NASA Center for AeroSpace Information, 301-621-0390.

13. ABSTRACT (Maximum 200 words)

Comparison of turbulence data taken in three separate flow nozzles, two with mixing enhancement features on their core nozzle, shows how the mixing enhancement features modify turbulence to reduce jet noise. The three nozzles measured were the baseline axisymmetric nozzle $3 \mathrm{BB}$, the alternating chevron nozzle, $3 \mathrm{~A}_{12} \mathrm{~B}$, with 6-fold symmetry, and the flipper tab nozzle $3 \mathrm{~T}_{24} \mathrm{~B}$ also with 6-fold symmetry. The data presented show the differences in turbulence characteristics produced by the geometric differences in the nozzles, with emphasis on those characteristics of interest in jet noise. Among the significant findings: the enhanced mixing devices reduce turbulence in the jet mixing region while increasing it in the fan/core shear layer, the ratios of turbulence components are significantly altered by the mixing devices, and the integral lengthscales do not conform to any turbulence model yet proposed. These findings should provide guidance for modeling the statistical properties of turbulence to improve jet noise prediction.

\section{SUBJECT TERMS}

15. NUMBER OF PAGES

Noise prediction; Aircraft; Turbulence models; Shear layers; Jet mixing; Flow;

Noise reduction; Jet aircraft noise; Turbulence

\begin{tabular}{|c|c|c|}
\hline $\begin{array}{c}\text { 17. SECURITY CLASSIFICATION } \\
\text { OF REPORT } \\
\text { Unclassified }\end{array}$ & $\begin{array}{c}\text { 18. SECURITY CLASSIFICATION } \\
\text { OF THIS PAGE } \\
\text { Unclassified }\end{array}$ & $\begin{array}{c}\text { 19. SECURITY CLASSIFICATION } \\
\text { OF ABSTRACT } \\
\text { Unclassified }\end{array}$ \\
\hline
\end{tabular}

NSN 7540-01-280-5500

Standard Form 298 (Rev. 2-89)

Prescribed by ANSI Std. Z39-18 298-102 